\title{
Accommodating the cyclist in the city
}

\author{
A. Furman \\ Faculty of Communication and Design, Ryerson University, Canada
}

\begin{abstract}
The latest merger of the neighbouring municipalities that currently form the City of Toronto occurred with the amalgamation of 1998. This new reality has many interesting situations that need addressing when considering a flexible and integrated bicycle network designed for the majority of residents and visitors. The portions of the city that follow a more suburban model do have the space for easy bicycle storage in the stock of single-family homes, yet the streets and outlying urban amenities aren't attached to a safe and convenient bicycling network. The mid and high rise towers that are aging in the suburbs and inner suburbs contend with the same lack of connections with bicycle lanes but have less storage options than the single family homes, and there are challenges to promoting safe biking and walking to schools. The inner city, and downtown revitalized areas that have been swept up with extensive condominium developments also suffer from a patchwork of bicycling street networks as well as limited parking options for those interested in cycling. Some of these challenges and opportunities of bicycling in the city of Toronto will be explored and presented as Toronto moves towards a city that accommodates all transportation choices, be they human-powered or otherwise.

Keywords: Toronto, circulation, bicycle, cycling advocacy, walking, Bike Plan, travel, active transportation, movement, network, bike lanes, bike storage, bicycle parking.
\end{abstract}

\section{Local active transportation challenges are also a global phenomenon}

"In (developed areas)...the primary task will be one of adapting existing building stock, public spaces, and transportation infrastructure to meet requirements that are very different from those that guided their initial production. These legacies of 
the industrial era, and of even earlier times, will require transformation in order to function effectively in the future" (W. J. Mitchell, E-Topia [1]).

One day, while looking through a stack of neighbourhood photos in the city archives, there was an image of a familiar street view from the 1950s that still had the local milk truck deliveries in the Toronto downtown along Davenport, a modern paved, 2-way street that was built upon an ancient shoreline trail. What made the image so interesting was the commingling of the street of cars, pedestrians, bicycles and the horse-drawn delivery wagon that was very much on its way out as a way of getting around this part of the city. Today, this historic image represents an interesting situation of differently-abled vehicles on the street and the legacy of the era of speed; a kind of thinking that all but eliminated anything that wasn't part of the fleet of automobiles from transportation and civic designs. Our contemporary city is in the early stages of adapting the street/road network into being a fully integrated and safer system designed for all transportation choices, however, it will not likely be a quick or painless transition. Compromise and some loss of comfort from our habits will ensue if Toronto is to go in the direction of a Copenhagen or Amsterdam in its city planning.

The above excerpt from Mitchell's book E-Topia prescribes a transformation of existing streets that define the public in built-up cities [1]. As in most populous cities in North America, most of the available street network has already been determined and any changes will necessitate some change of pattern in the sharing of the public space. Toronto has a real opportunity to shift from a car-dependent network into a city that accommodates all transportation choices, including the human-powered variety. This has been a very recent shift.

Toronto's urban cycling scene re-emerged from the dark ages into the early years of active transportation advocacy in the 1970s largely in part from the ripple effect of the oil crisis, and the popularity of the well-marketed 10-speed bicycle, creating the atmosphere for the proponents of active transportation in the city [2]. In 1974 Toronto cyclists were being threatened with losing the privilege of riding on city streets with the vehicles by the planning department, and it was suggested that they only remain on trails and sidewalk paths. This began cycling advocacy in Toronto and is part of the discourse on the use of space on city streets [3]. Cycling has been growing steadily but the city still encourages automobiles throughout and strategies used to promote active transportation such as luxury taxation for vehicles or reducing parking has not been implemented as strategies to lower automobile use. Since there is a limit to the amount of space in which the city may offer vehicles, this paper will revisit the strong vision for the 2001 Bike Plan and question what chance it has to be implemented in the near future.

As of 2010, the worldwide number of automobiles in use exceeded the 1 billion mark. Toronto's challenges with providing integrated, safe cycling lanes are not only local phenomena. Looking at the comments from the 2011 International Transport Forum, where representatives promoted the increase of automobiles in the country's plans stating that, in comparison to automobiles that "Cycling is a miniscule thing." B.K. Chaturvedi, of India's Planning Commission said "that's not the future" (taken from Daniel [4]). If the planning representative for what is estimated to become the most populous country by 2030 , believes that cycling 
infrastructure is not part of his country's sustainable goals, then more research needs to be done to challenge this widely-held opinion that cycling, and by extension active transportation, is a marginal activity and that it doesn't merit investment by the public sector. A few countries in Europe and Japan are the early adopters of cycling at a scale that works its way down from the federal to the local community level; some regions in the Americas are also doing an admirable job of redesigning their cities for cycling, and it is to these leaders that the active transportation advocates have been looking at for inspiration [5].

\section{A dramatic active transportation strategy and plan for the city delayed}

Modernity, inescapably tied to the motor-era, eclipsed bicycle infrastructure; it was simply forgotten about as an issue. Toronto, with only five decades since its introduction of a subway and 35 years since the very first bike lane, is still struggling with a proper bicycle infrastructure. Ironically, it has been the postmodern construction boom of tall residential towers whose urban residents are helping to reignite the stalled plans for active transportation in the city, starting with the inner core. The status quo of the automobile that dominates transportation planning decisions is visibly challenged most successfully in the warmer months with various public events that promote walking and cycling where the street and public space are reinvented through program [6]. Recent trends and studies indicate that the younger generations who are choosing to live in urban areas are eschewing the ownership model of a car, and instead prefer the freedom of choice that walking, car share, and cycling provides [7].

In Ontario, the Highway Traffic Act states that the bicycle is a vehicle, and so obeys all the same rules of the road as a car or truck. Toronto has 5,600 km of streets [8] and only $2 \%$ of this system is dedicated to bicycle lanes. This system, as shown in Figure 1, is still a patchwork system that provides only a few connected routes for human-powered locomotion that suffers from large gaps in the network. Naturally, much work has yet to be completed in order for the 2001 Toronto Bike Plan as adopted by council to be met. It would increase the current

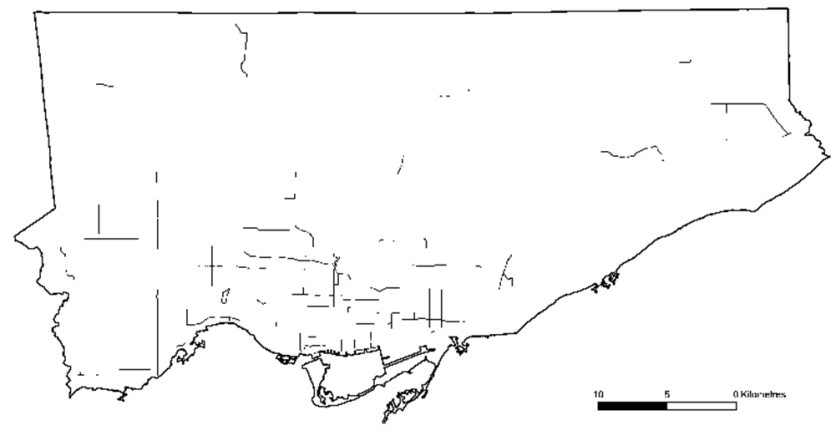

Figure 1: Current Toronto bicycle routes found across the city. The city covers approx. $240 \mathrm{sq} \mathrm{km}$. 
$114 \mathrm{~km}$ of bike lanes to meet the target of $495 \mathrm{~km}$ that was originally set for 2011 , with an original cost estimate of $\$ 11.6$ million proposed for the new bicycle lanes, and totaling $\$ 66.8$ million for all other trails and routes to encompass a remarkable, visionary $1000 \mathrm{~km}+$ active transportation network [9].

After the bicycling boom and civic restructuring of the 1970s, Toronto introduced early steps to improve bicycling lanes. Inspired by European examples, the tradition of building both bikeways and roadway networks began with local cycling advocacy groups. There were three classes of bikeways proposed, with the first class I being fully separated bike paths from other forms of traffic, and seen as the best solution if possible to implement from a safety and psychological point of view. Figure 2 shows the overlap of travel circles with a $3 \mathrm{~km}$ radius issuing from rapid transit facilities. The pedestrian and planning department used this map of the walk/cycle/rapid-transit modal-split to encourage healthier patterns by providing a convenient grid of options. This mapping study, along with the proposed 2011 bicycle lane grid network (Figure 3) would have placed Toronto at the vanguard of North American bicycling and active transportation infrastructure [9].

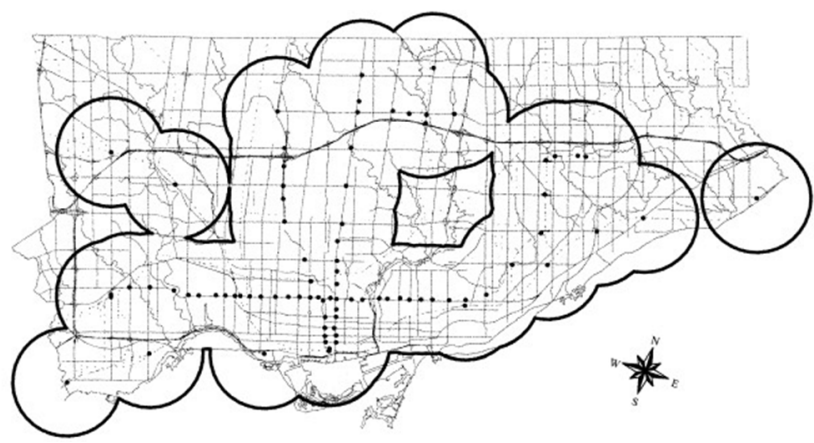

Figure 2: Area of the city that is within a $3 \mathrm{~km}$ rapid transit station. Source: Figure 8.2 Toronto Bike Plan, 2001, [2, p. 87].

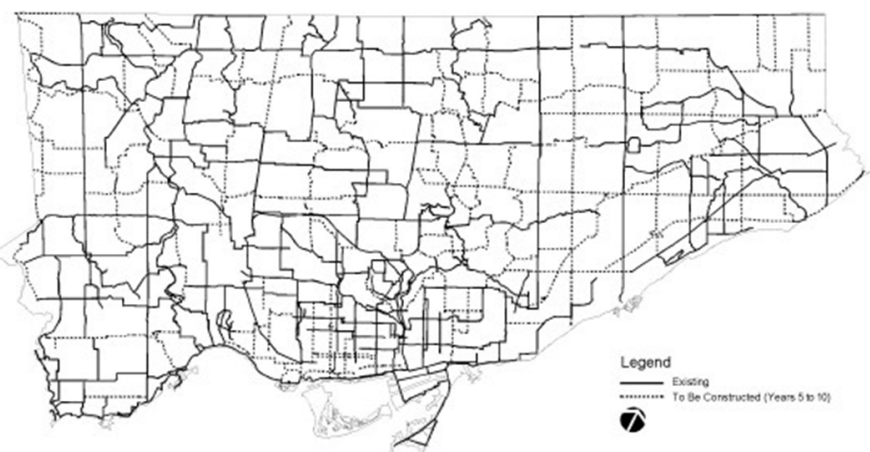

Figure 3: The 2001-2011 interconnected bikeway networks anticipated that never materialized. Compare with the current network mapped in 2014 in Figure 1. Source: Figure 10.3 Toronto Bike Plan, 2001, [2, p. 106]. 
Most residents have a general awareness of which areas in the city are pedestrian and cycling friendly, and the research demonstrates quite clearly that the zones that benefit the most from a pedestrian and cycling positive planning approach occur in the core of the city, where a comparison [10] of all neighbourhood walk scores for 2013 (Figure 4) and the daily cycling trips per person (Figure 5) demonstrate the concentration of walkable and cycling-friendly areas that have a better than average existing bike lane network [11].

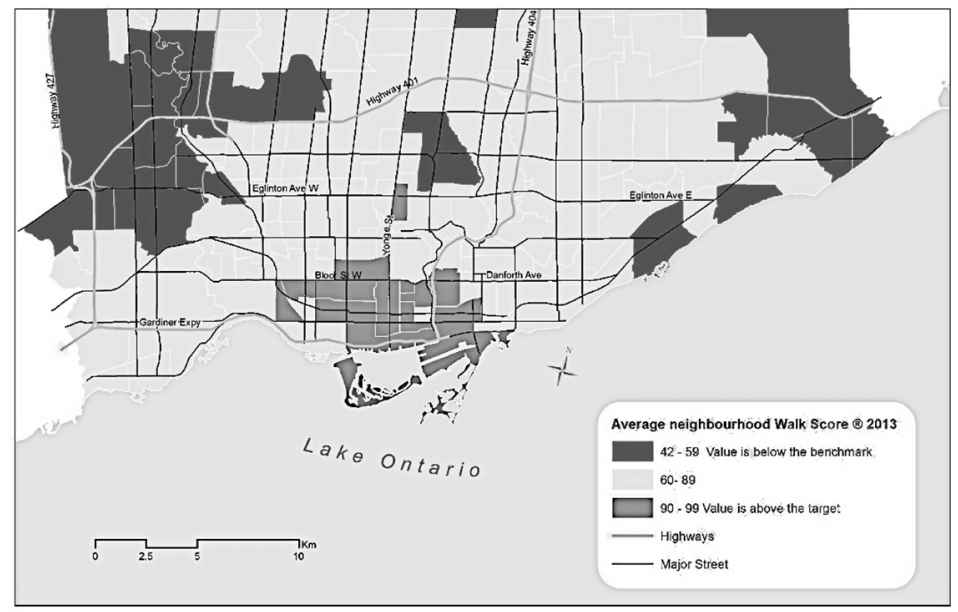

Figure 4: Average neighbourhood walk score for Toronto 2013. The medium grey tone indicates desirable high walk scores located in the city core. Source: Toronto Community Health Profiles, Urban HEART@ Toronto [10].

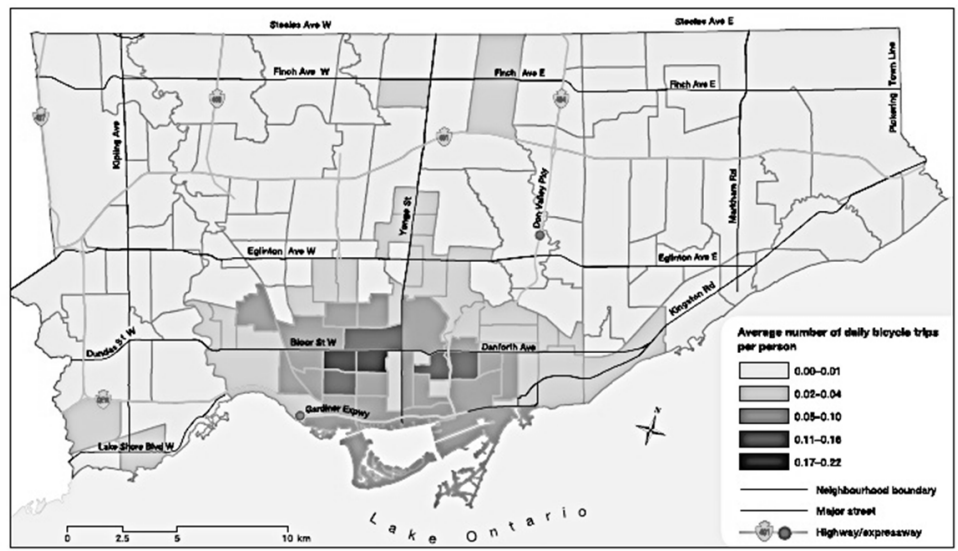

Figure 5: Daily cycling trips per person (Glazier et al. [21]). Source: [11, p. 40]. 


\section{Challenges in the existing amalgamated city}

A Canadian wide urban transportation indicator city study by the Transportation Association of Canada in 2001 found that Toronto rated lower for total kms of bicycle lanes per 1000 people when compared to cities that had much lower populations. The study concludes that Canadian cycling trips to work have increased by .1\% in the five years between 1996 and 2001 [12]. Amalgamation of the differently planned communities has created a difficult scenario for the city to work out. The 2001 Bike Plan was promoting health, safety, community, and a better quality of life for residents and visitors, leading to the inevitable question as to why didn't it achieve the goals set up early in the planning stages of 1999 ?

Perhaps it is a lack of collective political wills on the part of the people of Toronto, the similar 'disappearing trick' has also occurred with an international design competition to create a new urban park in the northern portion of the city with Downsview Park (2000). It was to be a 320-acre federal park meant to be in the same spirit of high public design as New Toronto City Hall (1958-65). Prophetically, in an essay by the director of urban design and planning at the time, he wondered why it was that not many citizens knew about the competition and winning project, stating that perhaps "suspicion lingers as to the federal commitment to complete the park over a fifteen-year period" [13]. Like clockwork, this urban park hasn't been developed in the last 15 years, and like the bike plan, it will require a champion to rekindle the original estimate for the construction and update the costs and to make public space an election platform issue.

Studies have shown that the use of the bicycle for short trips that are $5 \mathrm{~km}$ or less, the bicycle is the most efficient mode of urban transport, even when compared to the automobile, bus, and streetcar. Even for trips of $7 \mathrm{~km}$ in urban areas, cycling is almost as fast as driving, and it is faster than other modes of transportation. Walking is generally as fast as driving for trips of about $500 \mathrm{~m}$ and less, and it is faster than travel by bus for trips of up to $1.5 \mathrm{~km}$ [14]. According to the Pembina Institute, subway construction costs are $\$ 344$ million $/ \mathrm{km}$, with new roads estimated at $\$ 5$ million $/ \mathrm{km}$. Bicycle lane costs are estimated to be $\$ 550 / \mathrm{km}$ as part of road reconstruction, up to $\$ 1.2 \mathrm{million} / \mathrm{km}$ for widening an existing road for bicycle. However, this cost varies widely depending on the existing conditions and "depending on the type of separator, intersection treatments, presence of dedicated signals, and whether they are being retrofitted to an existing roadway or are part of new construction"'[14].

Approximate costs for providing the ubiquitous city Post and Ring bicycle parking racks as $\$ 160$ per post, and a dedicated enclosed bicycle parking facility equipped with lockers and showers is $\$ 3500$ per bicycle spot. This data shows that when compared to the construction of new highways and roadways, the cycling infrastructure is a fraction of the total cost a municipality would use in its budget. The research points to a common goal of improving the health of the Torontonian as well as offering healthy movement choices. As Jarrett Walker put it, personal mobility is key and it is a measure of a city's success since it is part of and also different than walking; it is "the freedom to move beyond your walking range" 
[15]. One could add that cycling mobility is also the desire to move about in the city in a safe and dignified manner, equal to all other forms of transit and public corridors.

Data from the Canadian Heart and Stroke Foundation states that $60 \%$ of Canadian adults are considered overweight or obese, along with $26 \%$ of Canadian children and youth and that " 1 in 3 obese children will be diabetic, and only $12 \%$ of Canadians' home-based trips (e.g. grocery store, work, school) are on foot or bicycle." where only $42 \%$ of adults are physically active in their leisure-time (Toronto Public Health, 2012 [11]). In Toronto the health indicators are not much better. Recent studies have shown that adults in the city that are 20 yrs or over have the second lowest level of physical activity when compared to 35 other health units in the province. $22 \%$ of Toronto teens are considered overweight or obese. According to the research (Bassett et al. (2008) [22]) shown in Figure 6, Canada has very low usage of active transportation when compared to other countries with low obesity rates among their residents.

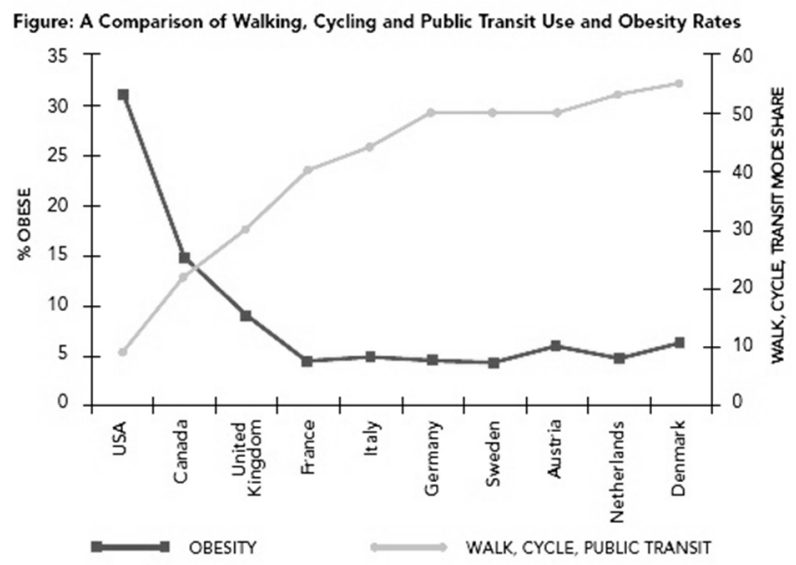

Figure 6: The Correlation between Activity and Obesity. Source: Transport Canada (2011) [14]. Data from Bassett et al. (2008) [14, p. 9].

The urban cyclist, when taking into account the materials of the construction of the vehicle and the energy required to use it, has about "one-tenth the ecological footprint of a commuting driver." Tod Litman's Transportation Affordability Study (2010) [23, p. 7] makes a case that for every cyclist; there would be associated cost savings for the city. "The average mid-size car driven 16,000 kilometres in a year costs about 46 cents per kilometre, or \$7,574 for the year, including gas, oil, maintenance, tires, insurance, license, registration, taxes, depreciation, and finance charges." And "overall, externalities increase the true cost of driving a car by about 75 cents per kilometre. Replacing a car trip with an active transportation trip saves individuals and society $\$ 1.70$ per kilometre, while a typical 1.25 kilometre bike trip would save $\$ 3.45$ " [16]. 
In Toronto's inner suburbs, many of the mid-century high-rises were developed in a climate that was hostile to the integration of paths and pedestrian networks. At the time there were no discussions for the provision of bicycling networks. In their final report to the city, Hess and Farrow (2010) [17] state that in the current aging stock of high-rise towers, there are over 200 distinct ethnicities in the city, with challenges for newcomers who must quickly adapt to the status-quo of the car-dependent city, even if they do not yet own their own car. The study states that auto ownership is desired and walking is what is done not for pleasure but of necessity. The study proves that "many participants expressed the desire to ride bicycles, but most agreed that it was too dangerous without dedicated cycling infrastructure." Hess and Farrow's research around Toronto's high-rise neighbourhoods demonstrates that " $28 \%$ of respondents disagreed or strongly disagreed that they feel safe from traffic when walking, and $29 \%$ disagreed that there are enough places to safely cross the large streets" [17]. Further studies need to compare the data on health, existing bicycle trails, and accident statistics to determine how to improve active transportation networks that connect these communities to the trails and urban bike lanes.

\section{Innovation with urbanity and cycling}

Norcliffe reminds us that in the Victorian era, cycling was all about embracing innovation, movement and the thrill of modernity. Being a futurist, and the importance of being seen in public, "to be seen frequently, to be seen to progress either in technology or fashion, and to update one's image regularly" was part of the early cyclist's motives $[18$, p. 252]. And the bicycle was "a geographically liberating machine, serving as a herald for even greater liberation in the age of the motorcar and aeroplane" that did offer more gender equality in public space [18, p. 222]. In Canada, lobbyist groups, such as the Canadian Wheelmen's Association worked to create the early paved roadways and bicycle trails in the 1890s. These groups were following road improvement movements from Europe and the United States [18, p. 150]. At this time cycling conflicts with pedestrians on the sidewalks were already a problem, and before the advent of the automobile, the system of interconnected city routes and rail/trail connections to the countryside were well established by the turn of the century.

Cycling advocacy groups have grown in number since the CM rides (Critical Mass) that have occurred starting in San Francisco, since 1992, an event in numerous city streets where in the evening, approximately at $6 \mathrm{pm}$ cyclists gather to ride together on city streets, effectively filling up the street with bicycle 'traffic' and making an event that is a discourse about the production of public space. Toronto has numerous organizations that work with the local levels of government and community to promote active transportation improvements. Sometimes the market itself creates the environment for change. Take the example of \#426 University Ave, a 42 storey, and 315-unit tower south of Dundas Street on University Avenue in the central core. It is the city's first large condominium development with no residential parking. The developer persuaded the city that the narrow footprint $(16.7 \times 38.1 \mathrm{~m})$ was too narrow to construct a typical parking 
ramp structure. Typically, the city permits a reduction of automotive parking spaces, up to $20 \%$ less of the total automotive parking spots, where 5 bicycle spots equal 1 automobile spot, in this case the city now has the precedent for a tall building to have only bicycle parking and a few rental cars for the residents to use.

Innovators who have questions how might bicycle parking and storage be transformative and testing the accepted typologies of use can be seen in Figure 7, an elegant industrial design/furniture storage unit for bicycles indoors, designed by Thomas Walde of Switzerland.

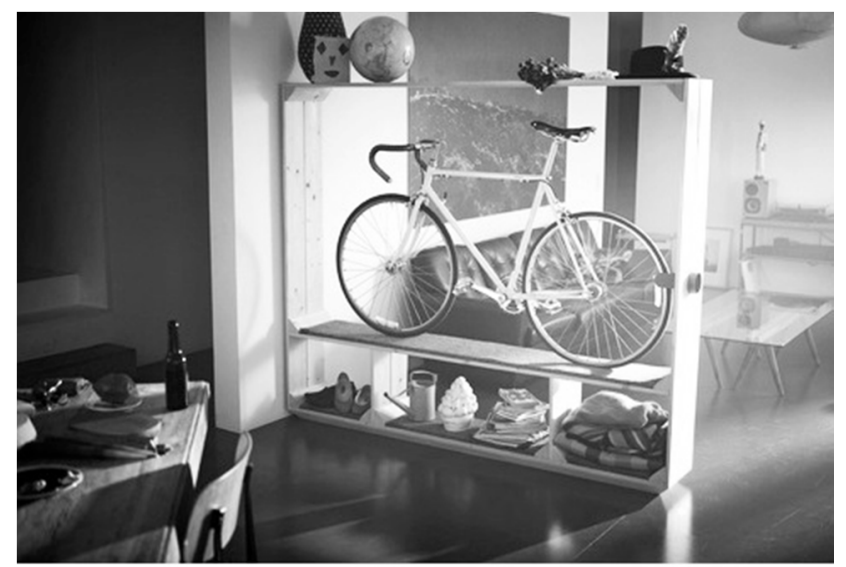

Figure 7: The Shoes Books and a Bike cycling parking solution by designer Thomas Walde, Postfossil Design of Switzerland. Photograph: Florian Kalotay, courtesy of the designer.

The Shoes Books and a Bike cycling parking solution by designer Thomas Walde of Switzerland treats the bicycle as an object of beauty to be showcased in a home or apartment. This design challenges many assumptions about cycling and the design of urban space since it is assumed that the resident takes the bicycle from the street up to their suite which may be on a floor that uses an elevator. Rules at condominiums often make it difficult to bring up large items in the elevator, but this attitude might be changing given the experimental developments found in designer projects such as the unique electric bicycle defined not as a bicycle but as a 'transportation appliance' pioneered by Henry Chong of Toronto. Chong's Revelo Bike (reveloelectric.com) 'reimagining transportation' using a $13.8 \mathrm{~kg}$ urban bicycle that challenges the definitions of motorized transportation and urban cycling by creating a new niche of urban rider. The stowed dimensions are $110 \times 75 \times 21$. It is a very manageable utility that bends barriers found in traditional electric vehicles and standard bicycles. These types of projects question traditional bicycle/electric car/rental vehicle models. The future of cities is set to be many fantastic variants of the bicycle. In the Pedaling Revolution by Mapes, the author ends with thoughts about innovation in transportation "there is a lot of room between the forty-pound bike and the two-thousand-pound car" [19]. 


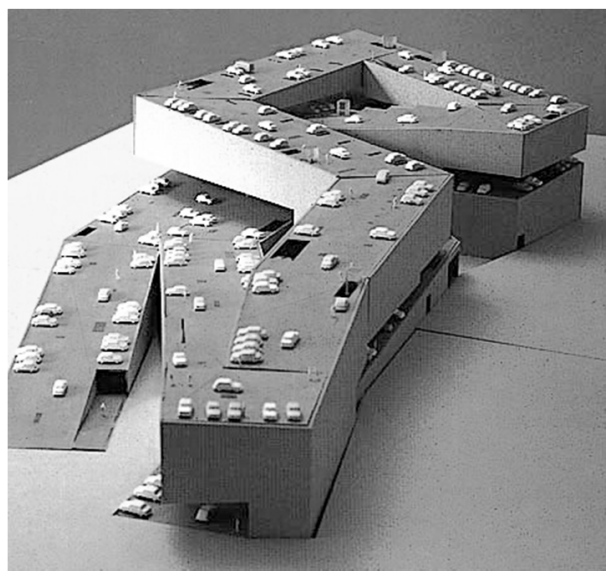

Figure 8: Parkhouse/Carstadt 1996 Pieter Bannenberg and Kamiel Klaasse. Image courtesy of Kamiel Klaasse, NL Architects.

In 1996 Pieter Bannenberg and Kamiel Klaasse proposed the Parkhouse/Carstadt for the oldest part of Amsterdam, a shopping destination. The model of the building is a large sloping parking lot, open to the elements, that grows from the street up to about 7 storeys (Figure 8) and then ramps back down. The cars are in effect the roof ornament and program with a building nestled underneath the ramp way. This integrated street + program with circulation was an early example of architectural work from the last few decades that explored the boundaries of the street, parking opportunities (for autos and bicycles) and all manner of programs. Bannenberg and Klaasse's proposal really gets at the heart of the issue in urban design and where it might go - the integration of the user with their various movement and active transportation options is a flexible system that is moving more towards convenience and the route a pedestrian takes, and further away from the subterranean parking garage that might be empty of cars and tomorrow's change-of-use projects.

\section{Conclusion}

For a true sustainable city, Sherilyn MacGregor holds to a village-model of change that starts "at the local level and be driven by community residents. People must be empowered to make changes, no matter how small, in the way they interact with each other and the earth" [20]. The city of Toronto is growing in population and it is clear that there is a will to integrate urban and suburban cycling into the daily habits of the residents and visitors of the city. Quick demonstration projects should be encouraged by the city to study how the population adopts to offering greater convenience in travel options. Automotive, freight, and downtown transit is already experiencing high demand on a network of streets and dedicated corridors in a highly mobile population that would be open to new ideas that would improve their travel time, enjoyment of the journey, and benefits to their health 
and well-being. In a fiscally challenging era partnerships between the public and private sector should be encouraged in order to build the network of safe routes for active transportation, and bicycling parking facilities. Toronto has a strong history of bicycling as a community activity, and further progress to bicycling integration in the city needs to include the local community groups and organizations that promote the healthy lifestyle in the Greater Toronto Area.

\section{Acknowledgement}

The author thanks the FCAD SRC Committee for support with this paper.

\section{References}

[1] Mitchell, W. J., E-Topia, The MIT Press, Cambridge, p. 154, 2000.

[2] The City of Toronto Bike Plan: Shifting Gears. June 2001. https:/www1.toronto.ca/City\%200f\%20Toronto/Transportation\%20Servi ces/Cycling/Files/pdf/B/bike_plan_full.pdf

[3] J. Pucher et al. Bicycling renaissance in North America? Recent trends and alternative policies to promote bicycling, Transportation Research Transportation Research Part A, Vol. 33, Nos. 7/8, pp. 625-654, Pergamon (C) 1999 Elsevier Science Ltd.

[4] Daniel, T., Number of Cars Worldwide Surpasses 1 Billion; Can The World Handle This Many Wheels? The Huffington Post, Canada, 2011. http://www.huffingtonpost.ca/2011/08/23/car-population_n_934291.html

[5] The Copenhagenize Index, Bicycle Friendly Cities, 2013. http://copenhagenize.eu/index/

[6] Toronto Cycling Events, City of Toronto, 2014. $\mathrm{http} / /$ www1.toronto.ca/wps/portal/contentonly?vgnextoid=a854970aa08c 1410VgnVCM10000071d60f89RCRD\&vgnextfmt=default

[7] Nicoletta, J., Driving Characteristics of the Young and Aging Population, Transportation Division, Statistics Canada. http://publications.gc.ca/ collections/Collection/Statcan/53F0007X/53F0007XIE.pdf

[8] The City of Toronto, Infrastructure, Toronto Facts, 2014. http://www1.toronto.ca/wps/portal/contentonly?vgnextoid=91d5f937de45 3410VgnVCM10000071d60f89RCRD\&vgnextchannel=57a12cc8174534 10VgnVCM10000071d60f89RCRD

[9] The City of Toronto Bike Plan: Shifting Gears, 2001. https:/www1.toronto.ca/City\%20Of\%20Toronto/Transportation\%20Servi ces/Cycling/Files/pdf/B/bike_plan_full.pdf

[10] Urban Heart @ Toronto: An evidence-based standard for measuring the wellbeing of Toronto's neighbourhoods. Centre for Research in Inner City Health, 2014. http://www.torontohealthprofiles.ca/urbanheartattoronto/ UrbanHeart_ExecutiveReport.pdf

[11] Lightman, D. et al., Toronto Public Health, Road to Health: Improving Walking and Cycling in Toronto, April 2012. http://www.toronto.ca/ health/hphe/pdf/roadtohealth.pdf 
[12] Hollingwood, B. et al. Urban Transportation Indicators THIRD SURVEY. Urban Transportation Council, Transportation Association of Canada (TAC), 2005. http://tac-atc.ca/sites/tac-atc.ca/files/site/complete.pdf

[13] Glover, R., City Making and the Making of Downsview Park, Case: Downsview Park Toronto. (ed. Julia Czerniak), Prestel Verlag, New York, pp. 34-39.

[14] Transport Canada, Active Transportation in Canada: a resource and planning guide. Government of Canada, 2011.

http://www.tc.gc.ca/media/documents/programs/atge.pdf

[15] Walker, J., Human Transit: How clearer thinking about public transit can enrich our communities and our lives, Island Press, Washington, pp.18-19, 2012.

[16] Lightman, D. et al., Toronto Public Health, Road to Health: Improving Walking and Cycling in Toronto, April 2012. http://www.toronto.ca/ health/hphe/pdf/roadtohealth.pdf

[17] P. Hess, J. Farrow., Walkability in Toronto's High-Rise Neighbourhoods Toronto Community Foundation. Final Report, 2010. http://www.janes walk.org/old/assets/uploads docs/Walkability Full Report.pdf

[18] Norcliffe, G. The ride to modernity: the bicycle in Canada, 1869-1900. The University of Toronto Press, p. 252, 2001.

[19] Mapes, J., Pedaling revolution: how cyclists are changing American cities. Oregon State University Press, p. 274, 2009.

[20] MacGregor, S., Change of plans: towards a non-sexist sustainable city. Garamond Press. Chapter: 'Planning Change: Not an End but a Beginning.' Ed. Eichler, Margrit. Toronto, pp. 157-167, 1995.

[21] Glazier R.H, Ross K., Gozdyra P., Creatore M.I., Booth G.L. Neighbourhood Infrastructure. In: Glazier R.H., Booth G.L., Gozdyra P., Creatore M.I., Tynan, M., editors. Neighbourhood Environments and Resources for Healthy Living - A Focus on Diabetes in Toronto: ICESAtlas. Toronto: Institute for Clinical Evaluative Sciences, 2007.

[22] David R. Bassett, Jr., John Pucher, Ralph Buehler, Dixie L. Thompson, and Scott E. Crouter, Walking, Cycling, and Obesity Rates in Europe, North America, and Australia. Journal of Physical Activity and Health, 2008, 5, pp. 795-814 @ 2008 Human Kinetics, Inc.

[23] Todd Litman, Transportation Affordability: Evaluation and Improvement Strategies. March 2014, Victoria Transport Policy Institute. http://www.vtpi.org/affordability.pdf 